Research article

Open Access

\title{
The PTPN22 1858C/T polymorphism is associated with anti-cyclic citrullinated peptide antibody-positive early rheumatoid arthritis in northern Sweden
}

\author{
Heidi Kokkonen ${ }^{1}$, Martin Johansson ${ }^{1}$, Lena Innala ${ }^{1}$, Erik Jidell2 and Solbritt Rantapää-Dahlqvist ${ }^{1}$
}

1Department of Rheumatology, University Hospital, SE-901 85 Umeå, Sweden

2Department of Transfusion Medicine, University Hospital, SE-901 85 Umeå, Sweden

Corresponding author: Solbritt Rantapää-Dahlqvist, solbritt.rantapaa.dahlqvist@medicin.umu.se

Received: 30 Jan 2007 Revisions requested: 19 Mar 2007 Revisions received: 10 May 2007 Accepted: 6 Jun 2007 Published: 6 Jun 2007

Arthritis Research \& Therapy 2007, 9:R56 (doi:10.1186/ar2214)

This article is online at: http://arthritis-research.com/content/9/3/R56

(c) 2007 Kokkonen et al.; licensee BioMed Central Ltd.

This is an open access article distributed under the terms of the Creative Commons Attribution License (http://creativecommons.org/licenses/by/2.0), which permits unrestricted use, distribution, and reproduction in any medium, provided the original work is properly cited.

\begin{abstract}
The PTPN22 1858C/T polymorphism has been associated with several autoimmune diseases including rheumatoid arthritis (RA). We have shown that carriage of the T variant (CT or TT) of PTPN22 in combination with anti-cyclic citrullinated peptide (anti-CCP) antibodies highly increases the odds ratio for developing RA. In the present study we analysed the association between the PTPN22 1858C/T polymorphism and early RA in patients from northern Sweden, related the polymorphism to autoantibodies and the HLA-DR shared epitope, and analysed their association with markers for disease activity and progression. The inception cohort includes individuals who also donated samples before disease onset. A case-control study was performed in patients $(n=505 ; 342$ females and 163 males) with early RA (mean duration of symptoms $=6.3$ months) and in population-based matched controls $(n=970)$ from northern Sweden. Genotyping of the PTPN22 1858C/T polymorphism was performed using a TaqMan instrument. HLAshared epitope alleles were identified using PCR sequence-
\end{abstract}

specific primers. Anti-CCP2 antibodies were determined using enzyme-linked immunoassays. Disease activity (that is, the number of swollen and tender joints, the global visual analogue scale, and the erythrocyte sedimentation rate) was followed on a regular basis (that is, at baseline and after 6, 12, 18 and 24 months). Both the 1858T allele and the carriage of $\mathrm{T}$ were associated with RA $\left(\chi^{2}=23.84, \mathrm{P}=0.000001\right.$, odds ratio $=$ $1.69,95 \%$ confidence interval $=1.36-2.11$; and $\chi^{2}=22.68, \mathrm{P}$ $=0.000002$, odds ratio $=1.79,95 \%$ confidence interval $=$ $1.40-2.29$, respectively). Association of the $1858 \mathrm{~T}$ variant with RA was confined to seropositive disease. Carriage of 1858T and the presence of anti-CCP antibodies was independently associated with disease onset at an earlier age $(P<0.05$ and $P$ $<0.01$, respectively), while the combination of both resulted in an even earlier age at onset. Smoking was identified as a risk factor independent of the $1858 \mathrm{~T}$ variant and anti-CCP antibodies.

\section{Introduction}

Recent studies have shown that a missense single nucleotide polymorphism resulting in a substitution of $\mathrm{T}$ for $\mathrm{C}$ at position 1858 in the protein tyrosine phosphatase nonreceptor type 22 (PTPN22) gene is associated with several autoimmune diseases including rheumatoid arthritis (RA) [1-3]. Several of the autoimmune diseases associated with the PTPN22 1858T variant are characterized by the presence of autoantibodies. These autoantibodies can be present several years before onset of the disease [4-6]. We have previously shown that a combination of the T variant of PTPN22 and anti-cyclic citrull- inated peptide (anti-CCP) antibodies in combination strongly predicts the future onset of RA with a specificity of $100 \%$ for the disease [7].

The association between the PTPN22 polymorphism and RA has been replicated by several groups studying different RA populations [1,8-11]. The first study on PTPN22 limited its association to rheumatoid factor-positive disease [1]. This polymorphism has subsequently been associated with both seropositive $[8,12]$ and seronegative disease $[13,14]$.

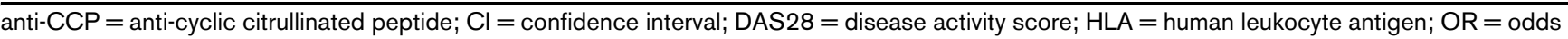
ratio; $\mathrm{PCR}=$ polymerase chain reaction; PTPN22 = protein tyrosine phosphatase nonreceptor type $22 ; \mathrm{RA}=$ rheumatoid arthritis; $\mathrm{SE}=$ shared epitope. 
In addition to genetic factors, environmental factors have been proposed to be of importance in the aetiology of RA. Several studies have suggested smoking to be the major environmental risk factor for RA $[15,16]$. HLA-shared epitope (SE) alleles and smoking have also recently been shown to act synergistically as risk factors, but only in anti-CCP antibody-positive patients with RA [17].

Considering our findings of a stronger predictive value of the combination of PTPN22 1858T variant with anti-CCP antibodies compared with HLA-SE and anti-CCP antibodies for development of RA in individuals before disease onset [7], the aim of the present study was to investigate the $1858 \mathrm{C} / \mathrm{T}$ polymorphism in relation to the presence of autoantibodies and HLASE alleles in an inception cohort of RA patients from northern Sweden for disease susceptibility, onset and inflammatory activity during the first 2 years. The individuals with blood samples before disease onset were included in the cohort of patients with early RA after disease onset.

\section{Materials and methods}

Patients from the four northern-most counties of Sweden with early RA (duration of symptoms $<12$ months) were consecutively included in the study and followed for 2 years. A total of 563 individuals fulfilling at least four of the seven American College of Rheumatology criteria for RA [18] were identified. The patients were assessed clinically at baseline and after 6 , 12,18 and 24 months using the 28-joint count for tender and swollen joints and a global visual analogue scale, and the erythrocyte sedimentation rate was measured. The Disease Activity Score (DAS28) was calculated [19]. Of the patients identified, 505 (342 females, 163 males) were willing to participate and donated DNA for this study. During the study period, $98.0 \%$ ( $n=448 / 457$ ) of the patients were treated for at least 6 months with disease-modifying antirheumatic drugs and $53.0 \%$ ( $n=244 / 460)$ of the patients were receiving prednisolone for at least 6 months. All patients were asked by questionnaire about their smoking habits, and were defined as smoker, nonsmoker ever or previous smoker. Demographic and clinical data of the patients at baseline are presented in Table 1.

From among the 505 patients with early RA, a subcohort of 85 individuals was identified as being donors to the Medical Biobank of northern Sweden before disease onset. The median time predating disease onset was 2.7 years (interquartile range $=1.1-6.0$ years). Serological analyses before and after disease onset were undertaken for these individuals. The Medical Biobank is population based, and conditions for recruitment into the cohorts and for the collection and storage of blood samples have previously been described in detail [5].

A total of 970 controls from the Medical Biobank of northern Sweden were randomly selected and matched for sex and age within a range of 5 years. The mean age of the controls was 58.2 years (range 25-79 years), and the distribution of males and females was $26.3 \%$ and $73.7 \%$, respectively. The Regional Ethics Committee at the University Hospital at Umeå approved this study and all participants gave their written informed consent.

The DNA from patients and controls ( $n=505$ and $n=970$, respectively) was extracted from ethylenediamine tetraacetic acid-treated whole blood using a standard salting-out method. The 5' nuclease assay was used to determine the PTPN22 $1858 \mathrm{C} / \mathrm{T}$ polymorphism (single nucleotide number rs2476601) as previously described [7]. The PCRs were performed according to the manufacturers' instructions, and detection of the different genotypes was made using an $A B I$ PRISM $^{\circledR} 7900$ HT Sequence Detector System (Applied Biosystems, Foster City, CA, USA). Data were processed using the SDS 2.1 software (Applied Biosystems). The different genotypes were verified by comparison with control samples of known genotype. Genotyping was successful for 504 of the patients.

\section{Table 1}

\section{Clinical and demographic data of the rheumatoid arthritis patients at baseline}

\begin{tabular}{|c|c|c|}
\hline & Patients $(n=505)$ & Controls $(n=970)$ \\
\hline Age (years) & $54.5 \pm 14.0$ & $57.4 \pm 11.6$ \\
\hline Symptom duration (months) & $6.3 \pm 2.8$ & -- \\
\hline Prednisolone treatment (number receving prednisolone/total number of patients) & $195 / 456(42.8)$ & -- \\
\hline Smoking ever (current, past), (number ever smoking/total number of patients) & $321 / 492(65.2)$ & $242 / 899(26.9)$ \\
\hline Anti-cyclic citrullinated peptide antibody-positive (number anti-CCP ab positive/total number of patients) & $318 / 468(67.9)$ & $5 / 347(1.4)$ \\
\hline Rheumatoid factor-positive (number RF positive/total number of patients) & $264 / 366(72.1)$ & -- \\
\hline
\end{tabular}

Data presented as the mean \pm standard deviation or number ratio (percentage). 
Table 2

\begin{tabular}{|c|c|c|c|c|c|c|c|c|c|}
\hline \multirow[t]{2}{*}{ Genotype } & \multicolumn{2}{|c|}{ Patients $(n=504)$} & \multicolumn{2}{|c|}{ Controls $(n=970)$} & \multirow[t]{2}{*}{$\chi^{2}$} & \multirow[t]{2}{*}{$P$ value } & \multirow[t]{2}{*}{$P_{\mathrm{c}}$ value } & \multirow[t]{2}{*}{ Odds ratio } & \multirow[t]{2}{*}{$95 \%$ confidence interval } \\
\hline & $n$ & $\%$ & $n$ & $\%$ & & & & & \\
\hline $\mathrm{CC}$ & 338 & 67.1 & 761 & 78.5 & 22.68 & 0.000002 & 0.00001 & 0.56 & $0.44-0.72$ \\
\hline CT & 151 & 30.0 & 196 & 20.2 & 17.53 & 0.000028 & 0.00014 & 1.69 & $1.31-2.18$ \\
\hline TT & 15 & 3.0 & 13 & 1.3 & 4.76 & 0.02907 & 0.14535 & 2.26 & $1.01-5.08$ \\
\hline $\mathrm{CT}+\mathrm{TT}$ & 166 & 33.0 & 209 & 21.5 & 22.68 & 0.000002 & 0.00001 & 1.79 & $1.40-2.29$ \\
\hline T allele & 181 & 18.0 & 222 & 11.4 & 23.84 & 0.000001 & 0.000005 & 1.69 & $1.36-2.11$ \\
\hline
\end{tabular}

$P_{\mathrm{c}}$, corrected $P$ value.

HLA-DRB1 genotyping was performed using PCR sequencespecific primers from the DR low-resolution kit and DRB $1{ }^{*} 04$ subtyping kits (Olerup SSP AB, Saltsjöbaden, Sweden) according to the previously described method [20]. The HLASE genes were defined as DRB1*0404 and DRB1*0401. Results of HLA-DRB1 genotyping were available for 500 patients and 170 randomly selected controls (mean age 53.0 \pm 8.9 years, $74.7 \%$ females and $25.3 \%$ males).

Anti-CCP2 antibodies ( $n=468$ patients) were determined using the Diastat kit from Axis-Shield Diagnostics (Dundee, UK) (cutoff value $=5$ units $/ \mathrm{ml}$ ). Rheumatoid factor of the $\operatorname{lgM}$ isotype was determined using the agglutination test with sentized sheep erythrocytes as originally described according to Waaler-Rose $(n=366)$.

The chi-square test was used for testing categorical data between groups. Student's $t$-test for independent samples was used to analyse continuous data. Binary logistic regression models were used to estimate predictive values of the 1858T variant of PTPN22, HLA-SE alleles, anti-CCP antibodies and smoking. Odds ratios (ORs) were calculated with $95 \%$ confidence intervals (Cls). All $P$ values refer to a two-sided test, and $P \leq 0.05$ was considered statistically significant. To correct for multiple comparisons, a corrected $P$ value $\left(P_{\mathrm{c}}\right)$ is also presented. The calculations were performed using the SPSS package (SPSS for Windows 14.0; SPSS Inc., Chicago, IL, USA). The area under the curve using DAS28 values for 24 months was calculated. Any missing values were assumed to be at random; consequently, the last value forward was used for missing DAS28 values at specific time points.

\section{Results}

The genotype distribution of the PTPN22 1858C/T polymorphism was in Hardy-Weinberg equilibrium in both the patient group and the control group. The genotype distributions differed significantly between patients and controls $\left(\chi^{2}=23.85\right.$, $P=0.000007)$. The 1858 T allele of PTPN22 was significantly higher in patients compared with controls, being $18.0 \%$ versus $11.4 \%$, respectively $\left(\chi^{2}=23.84,2\right.$ degrees of freedom, $P$ $=0.000001, P_{\mathrm{c}}=0.000005, \mathrm{OR}=1.69,95 \% \mathrm{Cl}=1.36-$ 2.11). The CT and TT genotypes were present in $33.0 \%$ of the patients and in $21.5 \%$ of the controls $\left(\chi^{2}=22.68, P=\right.$ $0.000002, P_{\mathrm{c}}=0.00001, \mathrm{OR}=1.79,95 \% \mathrm{Cl}=1.40-2.29$ ). The CC genotype was significantly decreased in patients compared with controls, at $67.1 \%$ versus $78.5 \%$, respectively $\left(\chi^{2}=22.68, P=0.000002, P_{\mathrm{c}}=0.00001, \mathrm{OR}=0.56,95 \%\right.$ $\mathrm{Cl}=0.44-0.72)($ Table 2).

When the patients were stratified according to autoantibody

\section{Table 3}

Comparison of PTPN22 1858 genotypes in rheumatoid arthritis patients stratified according to anti-cyclic citrullinated peptide (antiCCP) antibodies and rheumatoid factor with all controls

\begin{tabular}{|c|c|c|c|c|c|c|c|c|}
\hline & \multirow{2}{*}{$\begin{array}{l}\mathrm{CT}+\mathrm{TT} \\
\text { genotype, } n(\%)\end{array}$} & \multirow[t]{2}{*}{ CC genotype, $n(\%)$} & \multirow{2}{*}{$\begin{array}{l}\text { Minor allele } \\
\text { frequency }\end{array}$} & \multicolumn{5}{|c|}{ Cases versus all controls ${ }^{a}$} \\
\hline & & & & $\chi^{2}$ & $P$ value & $P_{\mathrm{c}}$ value & Odds ratio & $95 \%$ confidence interval \\
\hline Anti-CCP antibody-positive & $113(35.5)$ & $205(64.5)$ & 0.196 & 24.99 & 0.0000006 & 0.0000024 & 2.01 & $1.51-2.67$ \\
\hline Anti-CCP antibody-negative & $40(26.7)$ & $110(73.3)$ & 0.145 & 1.97 & 0.16046 & 0.64184 & 1.32 & $0.88-2.00$ \\
\hline Rheumatoid factor-negative & $28(27.5)$ & $74(72.5)$ & 0.142 & 1.87 & 0.17164 & 0.68656 & 1.38 & $0.85-2.23$ \\
\hline
\end{tabular}

$P_{\mathrm{c}}$, corrected $P$ value. a Controls presented in Table 2 
Table 4

Simple logistic regression analyses determining the odds ratios for different risk factors for rheumatoid arthritis

\begin{tabular}{lll}
\hline & Odds ratio & $95 \%$ confidence interval \\
\hline Anti-cyclic citrullinated peptide antibodies & 145.00 & $58.72-358.09$ \\
Smoking & 5.10 & $4.02-6.46$ \\
HLA-shared epitope & 2.04 & $1.43-2.91$ \\
T-carriage & 1.79 & $1.41-2.28$
\end{tabular}

status, the risk for RA in patients carrying the $1858 \mathrm{~T}$ variant was confined to those seropositive for anti-CCP antibodies or rheumatoid factor $\left(P=0.0000006, P_{\mathrm{c}}=0.0000024\right.$ and $P=$ $0.0000007, P_{\mathrm{c}}=0.0000028$, respectively) compared with controls (Table 3 ). In patients seronegative for these autoantibodies, carriage of the $1858 \mathrm{~T}$ variant did not increase the risk for RA ( $P=0.16$ and $P=0.17$, respectively) compared with controls. There were no significant differences in genotype distributions $(P=0.14$ and $P=0.16)$ or T-allele frequencies $(P=0.16$ and $P=0.17)$ in patients positive for compared with patients negative for anti-CCP antibodies or rheumatoid factors.

No significant difference in disease activity (DAS28) calculated by the area under the curve using DAS28 values for 24 months was detected between $1858 \mathrm{~T}$ carriers and noncarriers $(P=0.312)$. Carriers of the $1858 \mathrm{~T}$ variant, however, had significantly higher DAS at 6 months $\left(P<0.05, P_{\mathrm{c}}=0.20\right)$. Treatment of the disease at 6 months with disease-modifying antirheumatic drugs or prednisolone was similar in patients with or without the $1858 \mathrm{~T}$ variant (namely, $87 \%$ and $85 \%$, respectively, receiving disease-modifying antirheumatic drugs; and $41 \%$ and $44 \%$, respectively, receiving prednisolone).

The mean age at disease onset in patients carrying the 1858T variant $(n=166)$ was 3.0 years less than that in patients lacking this allele $(n=338$ ) (T carrier, 52.5 years; and non-T car- rier, 55.5 years; $P<0.05)$. Patients with anti-CCP antibodies $(n=318)$ had an earlier onset of the disease compared with patients without these autoantibodies $(n=150)$ (53.2 years for patients with anti-CCP antibodies and 56.8 years for patients without anti-CCP antibodies, $P<0.01$ ). A combination of the 1858T variant and anti-CCP antibodies contributed to an even earlier age of disease onset $(1858 \mathrm{~T}+$ anti-CCP antibodies, 51.5 years; compared with 55.2 years for those without this combination; $P<0.05)$.

The HLA-SE alleles were present in $282(56.4 \%)$ of the patients and in $66(38.8 \%)$ of the controls. There was a weak significant association of HLA-SE with the $1858 \mathrm{~T}$ variant of PTPN22 ( $\left.\chi^{2}=4.40, P=0.036\right)$, with a concordance rate of $52 \%$. The OR for RA in individuals with HLA-SE was 2.04 $(95 \% \mathrm{Cl}=1.43-2.91)$. Carriage of HLA-SE was significantly associated with the presence of anti-CCP antibodies $\left(\chi^{2}=\right.$ 35.54, $P<0.0001)$.

Anti-CCP antibodies were the strongest risk factor for development of RA in simple logistic regression analyses of the PTPN22 1858T variant, HLA-SE allele, anti-CCP antibodies and smoking, whereas the other risk factors had a rather similar OR for RA (Table 4).

Simple logistic regression analyses of the $1858 \mathrm{~T}$ variant, HLASE and smoking after stratification for anti-CCP antibodies

Table 5

Relative risk for developing rheumatoid arthritis in patients, stratified for anti-cyclic citrullinated peptide (anti-CCP) antibodies

\begin{tabular}{|c|c|c|c|c|}
\hline & \multicolumn{2}{|c|}{ Non-T carrier (CC) } & \multicolumn{2}{|l|}{$\mathrm{T}$ carrier $(\mathrm{CT}, \mathrm{TT})$} \\
\hline & Cases/controls & Relative risk (95\% confidence interval) & Cases/controls & Relative risk (95\% confidence interval) \\
\hline \multicolumn{5}{|c|}{ Anti-CCP antibody-positive } \\
\hline Smoking-negative & $59 / 511$ & 1.00 & $37 / 146$ & $2.17(1.41-3.35)$ \\
\hline Smoking-positive & $142 / 192$ & $6.29(4.51-8.77)$ & $73 / 50$ & $12.54(8.11-19.40)$ \\
\hline \multicolumn{5}{|c|}{ Anti-CCP antibody-negative } \\
\hline Smoking-negative & $47 / 511$ & 1.00 & $17 / 146$ & $1.36(0.80-2.33)$ \\
\hline Smoking-positive & $60 / 192$ & $3.71(2.51-5.46)$ & $23 / 50$ & $5.87(3.46-9.95)$ \\
\hline
\end{tabular}

The combination of carriage or not of the $1858 \mathrm{~T}$ variant of the PTPN22 gene and ever or never smoking were compared for groups stratified for anti-CCP antibodies. 


\begin{tabular}{|c|c|c|c|c|}
\hline & \multicolumn{2}{|l|}{ Nonsmoking } & \multicolumn{2}{|l|}{ Smoking } \\
\hline & Cases/controls & Relative risk (95\% confidence interval) & Cases/controls & Relative risk (95\% confidence interval) \\
\hline \multicolumn{5}{|l|}{ Anti-CCP antibody-positive } \\
\hline HLA-shared epitope-positive & $33 / 41$ & 1.00 & $71 / 49$ & $1.67(0.95-2.94)$ \\
\hline HLA-shared epitope-negative & $62 / 33$ & $2.05(1.12-3.75)$ & $143 / 21$ & $7.61(4.05-14.30)$ \\
\hline \multicolumn{5}{|l|}{ Anti-CCP antibody-negative } \\
\hline HLA-shared epitope-positive & $40 / 41$ & 1.00 & $52 / 49$ & $1.11(0.63-1.95)$ \\
\hline HLA-shared epitope-negative & $23 / 33$ & $0.71(0.37-1.38)$ & $31 / 21$ & $1.92(0.98-3.77)$ \\
\hline
\end{tabular}

The combination of carriage of HLA-shared epitope alleles or not, and ever or never smoking were compared for groups stratified for anti-CCP antibodies.

showed that smoking was a risk factor for RA in both the antiCCPantibody seropositive group and the anti-CCP antibodyseronegative group $(\mathrm{OR}=6.15,95 \% \mathrm{Cl}=4.68-8.07$ and $\mathrm{OR}$ $=3.51,95 \% \mathrm{Cl}=2.46-5.01$, respectively). The $1858 \mathrm{~T}$ variant and HLA-SE were risk factors for RA only in the anti-CCP antibody-positive group ( $\mathrm{OR}=2.00,95 \% \mathrm{Cl}=1.52-2.65$ and $\mathrm{OR}=3.11,95 \% \mathrm{Cl}=2.11-4.58$, respectively). In multiple regression analysis stratified for anti-CCP antibody and with $\mathrm{RA}$ as the dependent variable, the ORs were fairly equal for smoking (OR $=2.64,95 \% \mathrm{Cl}=1.71-4.08)$, for HLA-SE (OR $=3.34,95 \% \mathrm{Cl}=2.18-5.15)$ and for carriage of the $1858 \mathrm{~T}$ variant $(\mathrm{OR}=2.57,95 \% \mathrm{Cl}=1.54-4.29)$ in anti-CCP antibody-positive patients. In anti-CCP antibody-negative patients none of the variables remained significant.

Smoking was a risk factor for RA independent of anti-CCP antibodies and carriage of $1858 \mathrm{~T}$ in analyses with different combinations of anti-CCP antibodies, carriage of the $\mathrm{T}$ allele and smoking compared with nonsmokers without the 1858T variant (Table 5). HLA-SE was a risk factor for RA only in antiCCP antibody-positive patients; the relative risk of which was further increased in smokers compared with nonsmokers without HLA-SE (Table 6).

To analyse the relationship of different factors to anti-CCP antibodies as the dependent variable, multiple logistic regression analysis was performed with the variables $1858 \mathrm{~T}$ variant, HLA-SE allele and smoking. The $1858 \mathrm{~T}$ variant was not found to be significant (OR $=1.4295 \% \mathrm{Cl}=0.90-2.23$ ). Both smoking and HLA-SE predicted significantly the presence of anti-CCP antibodies, with the strongest impact from HLA-SE $(\mathrm{OR}=1.69,95 \% \mathrm{Cl}=1.11-2.57$ and $\mathrm{OR}=3.25,95 \% \mathrm{Cl}=$ 2.15-4.92, respectively).

There was no difference in the levels of anti-CCP antibodies in patients with or without the 1858T variant or carrying HLA-SE. In the subcohort of individuals for whom samples were available before disease onset $(n=85)$, anti-CCP antibodies were present in $32.1 \%$. Among those who lacked anti-CCP anti- bodies before disease onset but who turned anti-CCP antibody positive at disease onset, $62.5 \%$ were HLA-SE positive while $40 \%$ were HLA-SE negative (not significant). There was no relationship between carriage of the $T$ variant and developing anti-CCP antibodies at disease onset compared with not carrying the $\mathrm{T}$ variant ( $51.4 \%$ versus $52.4 \%$, respectively).

\section{Discussion}

In the present study, an association of the 1858T allele of PTPN22 with RA was found in 505 individuals from the four northern-most counties of Sweden with early RA,. In agreement with a study from southern Sweden and also other studies, this association was confined to patients with seropositive disease $[1,8,12]$.

Both the 1858T variant and HLA-SE alleles predicted RA, with an increase of the relative risk of each when present in combination with anti-CCP antibodies. This was also found in individuals who subsequently developed RA $[7,20]$. In the present study, in patients with early RA (that is, after disease onset), there was no significant association between the $1858 \mathrm{~T}$ variant and anti-CCP antibodies, whereas HLA-SE was strongly associated with anti-CCP antibodies. The increase in the number of anti-CCP antibody-positive patients after disease onset was greater among those carrying HLA-SE alleles. This was evaluated in a subcohort of individuals who were antiCCP-negative prior to onset of symptoms of disease but who became seropositive after disease onset; however, the number of individuals concerned was small and the difference did not reach statistical significance. These results could suggest that the 1858T variant is important before the disease has developed to a clinical stage, whereas HLA-SE is of significant importance when the disease has developed. Both these and our previous studies confirm that anti-CCP antibodies are the major predictor for RA. Taken together, these results could indicate that both genes contribute to the development of a disease, such as RA, by interfering in separate ways or at separate stages of pathogenesis (for example, by acting at various levels in the immunological process leading to the develop- 
ment of a disease). HLA-SE is believed to be involved in the antigen-presenting process whereas the role of the PTPN22 polymorphism for various parts of the immune system is not yet clear. The PTPN22 polymorphism is associated with several other autoimmune diseases, while HLA-SE is strongly related only to RA.

In contrast to most previous studies, we found that the PTPN22 1858T variant and HLA-SE are significantly associated $[8,10,12,14,21]$. One study has observed an association of the PTPN22 1858T variant and HLA-SE, but this was restricted to male patients [13].

Smoking has been shown to be the major environmental risk factor for RA $[15,16]$. In our study, smoking was a risk factor for RA independent of anti-CCP antibodies and the 1858T variant. In simple logistic regression analyses of anti-CCP antibody-negative patients, smoking was the only significant risk factor for RA, but this significance was lost in multiple logistic regression analysis. In the presence of anti-CCP antibodies, HLA-SE was a risk factor for RA; addition of smoking increased this risk approximately three-fold, which confirms the results presented in a previous study [17].

The genotype and allele frequencies of the PTPN22 polymorphism in patients and controls were higher in our study than those reported by some other groups [1,10,14,22]. Our results are consistent with the previously reported increasing south to north gradient in the frequency of the $1858 \mathrm{~T}$ variant in white European populations [23].

A gene-dosage effect of the 1858T allele has been suggested because a higher susceptibility for RA was found in individuals homozygous for the T allele $[8,13]$. We similarly found the OR for homozygous carriers of the $\mathrm{T}$ allele to be higher than that for heterozygous carriers (2.26 versus 1.69), suggesting a dose effect of the T allele of PTPN22. The number of homozygous carriers we were able to study, however, was small $(n=15)$.

Little is known about the effect of $1858 \mathrm{~T}$ on disease severity and activity. Most studies investigating the effect of $1858 \mathrm{~T}$ on clinical characteristics have found no association of $1858 \mathrm{~T}$ with disease severity or activity $[13,21,22]$. To analyse the effect of the $1858 \mathrm{~T}$ variant on disease activity we calculated the area under the curve using DAS28 values for 24 months, but no significant association of $1858 \mathrm{~T}$ with disease activity was found. There was a significant difference in disease activity at 6 months $(P<0.05)$,, when 1858 T carriers had a higher DAS28 than patients without the T variant. This difference was not due to a difference in treatment prescribed; instead, it is possible that carriers of $1858 \mathrm{~T}$ do not respond primarily as well to the treatment as non-T-carriers. The statistical significance did not remain, however, after correction for the number of performed tests.
It has been shown that the $1858 \mathrm{~T}$ variant contributes to an earlier age at onset of the disease [12,13]. We were able to confirm this finding; patients with the $T$ variant were significantly younger compared with patients not carrying the $T$ variant. The presence of anti-CCP antibodies, particularly in combination with $1858 \mathrm{~T}$, contributed to an earlier age at onset of the disease.

\section{Conclusion}

The PTPN22 1858C/T polymorphism was shown to be associated with early RA in the northern Swedish population and was confined to seropositive disease. Patients carrying the $1858 \mathrm{~T}$ variant had an earlier onset of the disease, particularly when in combination with anti-CCP antibodies. Furthermore, we could verify a south-north gradient with high frequencies of the PTPN22 1858 T variant in patients and controls. Smoking was, in this patient cohort, a risk factor for RA independent of the 1858T variant and seropositivity for anti-CCP antibodies.

\section{Competing interests}

The authors declare that they have no competing interests.

\section{Authors' contributions}

HK was the main investigator, carried out the genotyping and the statistics, and contributed to preparation of the manuscript. MJ and LI participated in the collection of the material and registration of the patient data. EJ was responsible for the HLA typing. SR-D is the principal investigator, responsible for the Biobank samples, designed the investigation, and participated in data collection, statistical analysis and drafting of the manuscript.

\section{Acknowledgements}

This study was supported by grants from the Swedish Research Council (K2003-74XD-14705-01), King Gustaf V's 80-Year Fund, the Swedish Rheumatism Association, the Swedish Heart-Lung Foundation and the Medical Faculty of Umeå University, Umeå, Sweden. The authors thank colleagues from the Rheumatology Department at the hospitals of Sunderbyn, Sundsvall and Östersund. Solveig Linghult and Thord Johansson are gratefully acknowledged for technical assistance. The staff of the Medical Biobank, and of the Early Arthritis Clinic, Department of Rheumatology, University Hospital of Umeå are also gratefully acknowledged.

\section{References}

1. Begovich $A B$, Carlton VE, Honigberg LA, Schrodi SJ, Chokkalingam AP, Alexander HC, Ardlie KG, Huang Q, Smith AM, Spoerke $\mathrm{JM}$, et al:: A missense single-nucleotide polymorphism in a gene encoding a protein tyrosine phosphatase (PTPN22) is associated with rheumatoid arthritis. Am J Hum Genet 2004, 75:330-337.

2. Bottini N, Musumeci L, Alonso A, Rahmouni S, Nika K, Rostamkhani M, MacMurray J, Meloni GF, Lucarelli P, Pellecchia M, et al.: A functional variant of lymphoid tyrosine phosphatase is associated with type I diabetes. Nat Genet 2004, 36:337-338.

3. Criswell LA, Pfeiffer KA, Lum RF, Gonzales B, Novitzke J, Kern M, Moser KL, Begovich AB, Carlton VE, Li W, et al.: Analysis of families in the multiple autoimmune disease genetics consortium (MADGC) collection: the PTPN22 620W allele associates with 
multiple autoimmune phenotypes. Am J Hum Genet 2005, 76:561-571.

4. Arbuckle MR, McClain MT, Rubertone MV, Scofield RH, Dennis GJ, James JA, Harley JB: Development of autoantibodies before the clinical onset of systemic lupus erythematosus. $N$ Engl $J$ Med 2003, 349:1526-1533.

5. Rantapaa-Dahlqvist S, de Jong BA, Berglin E, Hallmans G, Wadell $G$, Stenlund $H$, Sundin $U$, van Venrooij WJ: Antibodies against cyclic citrullinated peptide and IgA rheumatoid factor predict the development of rheumatoid arthritis. Arthritis Rheum 2003, 48:2741-2749.

6. Strieder TG, Prummel MF, Tijssen JG, Endert E, Wiersinga WM: Risk factors for and prevalence of thyroid disorders in a crosssectional study among healthy female relatives of patients with autoimmune thyroid disease. Clin Endocrinol (Oxf) 2003, 59:396-401.

7. Johansson M, Arlestig L, Hallmans G, Rantapaa-Dahlqvist S: PTPN22 polymorphism and anti-cyclic citrullinated peptide antibodies in combination strongly predicts future onset of rheumatoid arthritis and has a specificity of $100 \%$ for the disease. Arthritis Res Ther 2005, 8:R19.

8. Lee AT, Li W, Liew A, Bombardier C, Weisman M, Massarotti EM, Kent J, Wolfe F, Begovich AB, Gregersen PK: The PTPN22 R620W polymorphism associates with RF positive rheumatoid arthritis in a dose-dependent manner but not with HLA-SE status. Genes Immun 2005, 6:129-133.

9. Hinks A, Barton A, John S, Bruce I, Hawkins C, Griffiths CE, Donn R, Thomson W, Silman A, Worthington J: Association between the PTPN22 gene and rheumatoid arthritis and juvenile idiopathic arthritis in a UK population: further support that PTPN22 is an autoimmunity gene. Arthritis Rheum 2005, 52:1694-1699.

10. Orozco G, Sanchez E, Gonzalez-Gay MA, Lopez-Nevot MA, Torres B, Caliz R, Ortego-Centeno N, Jimenez-Alonso J, Pascual-Salcedo $\mathrm{D}$, Balsa $\mathrm{A}$, et al: Association of a functional single-nucleotide polymorphism of PTPN22, encoding lymphoid protein phosphatase, with rheumatoid arthritis and systemic lupus erythematosus. Arthritis Rheum 2005, 52:219-224.

11. Zhernakova $A$, Eerligh $P$, Wijmenga $C$, Barrera $P$, Roep $B O$, Koeleman BP: Differential association of the PTPN22 coding variant with autoimmune diseases in a Dutch population. Genes Immun 2005, 6:459-461.

12. Plenge RM, Padyukov L, Remmers EF, Purcell S, Lee AT, Karlson EW, Wolfe F, Kastner DL, Alfredsson L, Altshuler D, et al:: Replication of putative candidate-gene associations with rheumatoid arthritis in $>4,000$ samples from North America and Sweden: association of susceptibility with PTPN22, CTLA4, and PADI4. Am J Hum Genet 2005, 77:1044-1060.

13. Pierer $M$, Kaltenhauser $S$, Arnold $S$, Wahle $M$, Baerwald $C$, Hantzschel H, Wagner U: Association of PTPN22 1858 singlenucleotide polymorphism with rheumatoid arthritis in a German cohort: higher frequency of the risk allele in male compared to female patients. Arthritis Res Ther 2006, 8:R75.

14. Simkins HM, Merriman ME, Highton J, Chapman PT, O'Donnell JL, Jones PB, Gow PJ, McLean L, Pokorny V, Harrison AA, et al.: Association of the PTPN22 locus with rheumatoid arthritis in a New Zealand Caucasian cohort. Arthritis Rheum 2005, 52:2222-2225.

15. Silman AJ, Newman J, MacGregor AJ: Cigarette smoking increases the risk of rheumatoid arthritis. Results from a nationwide study of disease-discordant twins. Arthritis Rheum 1996, 39:732-735.

16. Uhlig T, Hagen KB, Kvien TK: Current tobacco smoking, formal education, and the risk of rheumatoid arthritis. J Rheumatol 1999, 26:47-54.

17. Klareskog L, Stolt $P$, Lundberg K, Kallberg H, Bengtsson $C$, Grunewald J, Ronnelid J, Harris HE, Ulfgren AK, Rantapaa-Dahlquist S, et al:: A new model for an etiology of rheumatoid arthritis: smoking may trigger HLA-DR (shared epitope)-restricted immune reactions to autoantigens modified by citrullination. Arthritis Rheum 2006, 54:38-46.

18. Arnett FC, Edworthy SM, Bloch DA, McShane DJ, Fries JF, Cooper NS, Healey LA, Kaplan SR, Liang MH, Luthra HS, et al:: The American Rheumatism Association 1987 revised criteria for the classification of rheumatoid arthritis. Arthritis Rheum 1988, 31:315-324.
19. Prevoo ML, van 't Hof MA, Kuper HH, van Leeuwen MA, van de Putte LB, van Riel PL: Modified disease activity scores that include twenty-eight-joint counts. Development and validation in a prospective longitudinal study of patients with rheumatoid arthritis. Arthritis Rheum 1995, 38:44-48.

20. Berglin E, Padyukov L, Sundin U, Hallmans G, Stenlund H, Van Venrooij WJ, Klareskog L, Dahlqvist SR: A combination of autoantibodies to cyclic citrullinated peptide (CCP) and HLADRB1 locus antigens is strongly associated with future onset of rheumatoid arthritis. Arthritis Res Ther 2004, 6:R303-R308.

21. Harrison P, Pointon JJ, Farrar C, Brown MA, Wordsworth BP Effects of PTPN22 C1858T polymorphism on susceptibility and clinical characteristics of British Caucasian rheumatoid arthritis patients. Rheumatology (Oxford) 2006, 45:1009-1011.

22. van Oene M, Wintle RF, Liu X, Yazdanpanah M, Gu X, Newman B, Kwan A, Johnson B, Owen J, Greer W, et al.: Association of the lymphoid tyrosine phosphatase R620W variant with rheumatoid arthritis, but not Crohn's disease, in Canadian populations. Arthritis Rheum 2005, 52:1993-1998.

23. Gregersen PK, Lee HS, Batliwalla F, Begovich AB: PTPN22: setting thresholds for autoimmunity. Semin Immunol 2006, 18:214-223. 